\title{
Kontrol Kecepatan Motor Penggerak Feeder Pada Mesin Pencacah Jerami Untuk Sistem Reaktor Biogas Berbahan Baku Jerami
}

\section{Driving Motor Speed Control Feeder On Counting Machines Straw For Biogas Reactor System Made From Straw}

\author{
Kartika $^{1)}$,Roswaldi Sk ${ }^{1}$, Amril $^{1)} \&$ Sandra ${ }^{2)}$ \\ ${ }^{1)}$ Jurusan Teknik Elektro Politeknik Negeri Padang Kampus Limau Manis Padang 25163 \\ Telp. 0751-72590 Fax.0751-72576 Email: kartika_munir@yahoo.com \\ ${ }^{2)}$ Teknologi Hasil Pertanian, Fakultas Teknologi Pertanian Unibraw, \\ Jl. Haryono MT, Malang.
}

\begin{abstract}
The production of one ton of rice straw will produce $250 \mathrm{~kg}$ of dry hay (Isni, 2011). A sizeable amount, straw as one of the ingredients that are very effectively used as raw material for biogas. Straw into biogas conversion value reaches 250-350 liter / kg dry weight (Arati, 2009). For a perfect straw metabolism, staw should be cut first. Enumeration is done manually is less efficient because the enumeration is done by using a knife to cut hay will produce a piece of straw that are not uniform. Good hay cutting measure is about $2-5 \mathrm{~cm}$. If the straw enumeration is done by machine, then it takes the feeder to the cutting machine tool that can feed the straw so that the resulting size of $2-5 \mathrm{~cm}$. To make the necessary feeder, conveyor, DC motors, magnetic clutch and infrared sensors. Conveyor serves as a carrier of straw, DC motors as actuators, magnetic clutch as conveyor control and infrared sensor as a measure of pieces of straw. After testing, show that it works and works well.
\end{abstract}

Keywords : Straw, feeder, DC motor and a magnetic clutch.

\section{PENDAHULUAN}

Dalam 10 tahun terakhir, Indonesia mengalami penurunan produksi minyak nasional yang disebabkan menurunnya secara alamiah (natural decline) cadangan minyak pada sumur-sumur yang berproduksi. Di lain pihak, pertambahan jumlah penduduk akan menyebabkan kebutuhan energi selalu meningkat tiap tahunnya. Untuk mengatasi ancaman kelangkaan energi maka perlu dikembangkan alternative energy baru terbarukan, salah satunya adalah biogas (Isni, 2011).

Di Indonesia, jerami merupakan limbah pertanian dari salah satu tanaman makanan pokok nomor satu yang belum dimanfatkan secara optimal. Jika dilirik dari junlahnya, produksi jerami dari satu ton beras akan menghasilkan $250 \mathrm{~kg}$ jerami kering (Isni, 2011). Jumlah yang cukup besar ini menjadikan jerami sebagai salah satu bahan yang sangat efektif digunakan untuk bahan baku biogas. Nilai konversi jerami menjadi biogas mencapai 250 - 350 liter/kg berat kering (Arati, 2009).

Untuk membantu proses

metabolisme dari bakeri metanogenesis berkembang biak sempurna, maka sebelum jerami dimasukkan kedalam reactor biogas, jerami harus dipotong-potong terlebih dahulu. Pencacahan yang dilakukan secara tradisional kurang efisien karena pencacahan yang dilakukan dengan memotong jerami menggunakan sabit akan menghasilkan potongan jerami yang tidak seragam dan ukuran yang kurang baik. Ukuran pemotongan jerami yang baik adalah sekitar 2-5 cm. Jika pencacahan jerami dilakukan dengan mesin, maka dibutuhkan alat pengumpan jerami ke mesin pemotong yang dapat mengumpan jerami sehingga dihasilkan ukuran $2-5 \mathrm{~cm}$. Selain itu, ketika feeder telah mengumpan jerami pada ukuran yang diinginkan, feeder tersebut harus berhenti agar jerami dapat terpotong oleh pencacah. Setelah jerami 
terpotong, barulah feeder diperbolehkan bergerak kembali untuk mengumpan jerami. Maka dari itu motor penggerak feeder pengumpan jerami harus diatur gerakannya agar dapat berjalan sesuai dengan ukuran pemotongannya.

Pada penelitian ini menggunakan motor DC, jika motor DC di on / off, maka akan menyebabkan motor cepat rusak. Maka pada penelitian ini untuk mengatur gerak dari feeder digunakan sebuah clatch magnet, fungsinya sama dengan sistem pengereman magnet. Motor DC tetap berputar, tetapi sumbu sebagai penggerak feeder berputar berdasarkan pengaturan dari clatch magnet, sehingga motor DC beroperasi terus menerus.

\section{Feeder}

Feeder merupakan suatu alat yang digunakan untuk mengumpan suatu material dari satu proses ke proses lainnya. Feeder merupakan bagian dari belt conveyor yaitu peralatan penanganan material mekanis yang bergerak dari satu lokasi ke lokasi lain.

Feeder pada dasarnya merupakan peralatan yang cukup sederhana. Alat tersebut terdiri dari sabuk yang tahan terhadap pengangkutan material. Sabuk yang digunakan pada feeder ini dapat dibuat dari berbagai jenis bahan misalnya dari karet, plastik, kulit ataupun logam yang tergantung dari jenis dan sifat bahan material yang akan diangkut atau diumpan.

Pada mesin pencacah jerami, fedeer adalah peralatan yang berfungsi mengatur aliran dan pemisah bahan - bahan serta penerima bahan baku. Fungsi utama feeder adalah mengatur aliran material yang akan diumpan ke mesin pencacah jerami.

Pada mesin pencacah jerami, feeder digunakan untuk mengarahkan jerami ke pisau pemotong jerami. Untuk menggerakkan feeder digunakan motor DC yang gerakannya dikontrol dengan menggunakan kopling magnet yang suplai arusnya diatur oleh sensor infra red.

Didunia industri feeder yang digunakan adalah feeder yang memiliki kapasitas yang besar. Beberapa tipe feeder antara lain (Santoso, 2011):

a) Appron feeder, Apron feeder merupakan jenis pesawat pemindah bahan yang mempunyai kapasitas pemindahan yang besar, dalam proses penyediaan bahan baku apron feeder berfungsi sebagai pengumpan bagi belt conveyor, kemudian belt conveyor akan memindahkan material tersebut untuk diproses lebih lanjut. Dalam pelaksanaannya apron feeder dapat dioperasikan dengan dua system control, yaitu dengan system control secara otomatis dan system control secara manual, dimana dengan system control tersebut feeder bisa dikontrol kapasitasnya sesuai kebutuhan.

b) Reciprocating plate feeder (plat pengumpan bolak - balik), biasanya dipakai untuk material yang diambil dari gravel pit, material ini umumnya berukuran kecil yang kadang - kadang tidak perlu pemecahan sehingga harus dikelurkan dari material yang besar.

\section{Magnetic Clutch (Kopling Magnet)}

Magnetic Clutch (kopling magnet) adalah suatu alat yang memanfaatkan medan magnet dari aliran listrik pada pengoperasiaannya. Pada AC kendaraan, kopling magnet berfungsi sebagai penghubung putaran mesin mobil dengan kompressor AC. Peralatan intinya adalah stator, rotor dan pressure plate. Pada gambar 1 berikut adalah bentuk kopling magnet yang dipakai pada AC mobil :

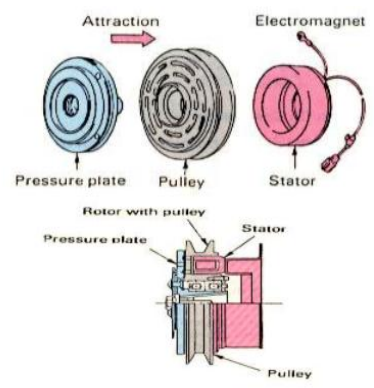

Gambar 1. Konstruksi kopling magnet Kompresor

(sumber "Direktorat Jendral Pembinaan Pelatihan Dan Produktifitas") 
Dari gambar 1 terlihat bahwa konstruksi kopling magnet terdiri atas puli yang terpasang pada poros kompressor dengan bantalan diantaranya menyebabkan puli dapat bergerak dengan bebas. Sedang stator terikat dengan kompressor housing dan pressure plate terpasang mati pada poros kompressor.

Prinsip kerja kopling magnet ini yaitu puli kompressor selalu berputar oleh perputaran mesin melalui tali kipas pada saat mesin hidup. Dalam posisi switch AC off, kompressor tidak akan berputar, dan kompressor hanya akan berputar apabila switch AC dalam posisi hidup (on) hal ini disebabkan oleh arus listrik yang mengalir ke stator coil akan mengubah stator coil menjadi magnet listrik yang akan menarik pressure plate dan bidang singgungnya akan bergesekan dan saling melekat dalam satu unit (Clutch assembly) memutar kompresor.

\section{Elektromagnetic}

Pada sekitar tahun 1860, James Clark Maxwell (1831-1878), seorang fisikawan dari Scotlandia berhasil menemukan kaitan antara masalah tentang listrik dan magnetisme. Kaitan yang pertama adalah muatan listrik yang mengalir (arus listrik) dapat menghasilkan medan magnet di sekitar kawat berarus tersebut, seperti dijelaskan dalam Hukum Biot-Savart atau hukum Ampere. Kaitan yang kedua adalah perubahan medan magnet yang dapat menghasilkan gaya gerak listrik terinduksi, seperti dijelaskan dalam Hukum Faraday (Utomo, 2011).

Banyak alat-alat listrik yang bekerjanya atas dasar kemagnetan listrik. Misalnya bel listrik, telepon, telegraf, alat penyambung atau relai, kunci pintu listrik, detektor logam dan loudspeaker. Alat-alat ukur seperti amperemeter, voltmeter dan galvanometer dapat dijelaskan dengan prinsip kemagnetan listrik (Efendi, 2007).

Pada bel listrik prinsip kerja elektromagnetik adalah sebagai berikut: Bel listrik terdiri dari dua electromagnet dengan setiap selenoida dililitkan pada arah yang berlaianan. Apabila saklar ditekan, arus listrik akan mengalir melalui solenoid. Teras besi akan menjadi magnet dan menarik kepingan besi lentur dan pengetuk akan memukul bel (lonceng) dan menghasilkan bunyi. Tarikan kepingan besi lentur oleh electromagnet akan memisahkan titik sentuh dan sekrup pengatur yang berfungsi sebagai interuptor. Arus listrik akan putus dan teras besi hilang kemagnetannya. Kepingan besi lentur akan kembali pada kedudukan semula. Teras besi akan menjadi magnet dan menarik kepingan besi lentur dan pengetuk akan memukul bel (lonceng) dan menghasilkan bunyi kembali. Proses ini berulang-ulang sangat cepat dan bunyi lonceng terus terdengar.

\section{Sensor Infra Red}

Pada dasarnya rangkaian sensor infra red ini terdiri dari 2 bagian, yaitu bagian transmitter menggunakan infrared dan bagian receiver menggunakan foto dioda. Rangkaian transmitter berfungsi untuk memancarkan radiasi infra merah dan rangkaian receiver berfungsi untuk menerima radiasi infra merah.

\section{Pemancar Sinyal Infra Merah}

Cahaya infra merah merupakan cahaya yang tidak tampak. Jika dilihat dengan spektroskop cahaya maka radiasi cahaya infra merah akan terlihat pada spektrum elektromagnet dengan panjang gelombang di atas panjang gelombang cahaya merah. Radiasi inframerah memiliki panjang gelombang antara $700 \mathrm{~nm}$ sampai 1 mm dan berada pada spektrum berwarna merah. Dengan panjang gelombang ini maka cahaya infra merah tidak akan terlihat oleh mata namun radiasi panas yang ditimbulkannya masih dapat dirasakan/dideteksi (Hermawan, 2010).

Sinar infra merah yang dipancarkan oleh pemancar infra merah tentunya mempunyai aturan tertentu agar data yang dipancarkan dapat diterima dengan baik pada penerima. Oleh karena itu baik di pengirim infra merah maupun penerima infra merah harus mempunyai aturan yang sama dalam mentransmisikan (bagian 
pengirim) dan menerima sinyal tersebut kemudian mendekodekannya kembali menjadi data biner (bagian penerima). Komponen yang dapat menerima infra merah ini merupakan komponen yang peka cahaya yang dapat berupa dioda (photodioda) atau transistor (phototransistor). Komponen ini akan merubah energi cahaya, dalam hal ini energi cahaya infra merah, menjadi pulsapulsa sinyal listrik. Komponen ini harus mampu mengumpulkan sinyal infra merah sebanyak mungkin sehingga pulsa-pulsa sinyal listrik yang dihasilkan kualitasnya cukup baik (Simatupang, 2010).

Gambar 2 menunjukkan bentuk LED Infra Red yang sering digunakan dalam pembuatan rangkaian transmitter :

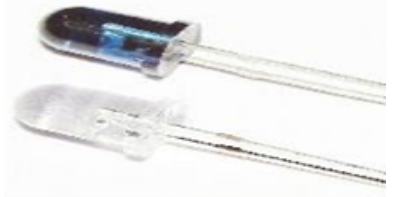

Gambar 2. LED Infra Red

Infra merah dapat dibedakan menjadi tiga daerah yakni :

1. Near Infra Merah...............0,75 $1,5 \mu \mathrm{m}$

2. Mid Infra Merah...................1,50 $10 \mu \mathrm{m}$

3. Far Infra Merah...................10 $100 \mu \mathrm{m}$

Sifat-sifat cahaya infra merah (Hermawan, 2010):

1. Tidak tampak manusia.

2. Tidak dapat menembus materi yang tidak tembus pandang.

3. Dapat ditimbulkan oleh komponen yang menghasilkan panas

Pada pemancar sinyal infrared digunakan IC NE555. IC NE555 merupakan salah satu komponen elektronika yang cukup terkenal, sederhana dan serba guna dengan ukurannya yang kurang dari $0,5 \mathrm{~cm} 3$. Pada dasarnya aplikasi utama IC NE555 ini digunakan sebagai timer (pewaktu) dengan operasi monostable dan pulse generator (pembangkit pulsa) dengan operasi astable. Selain itu dapat juga digunakan sebagai time delay generator dan sequential timing.
Bentuk konfigurasi pin dari IC NE 555 ini dapat dilihat dari gambar 3 berikut ini :

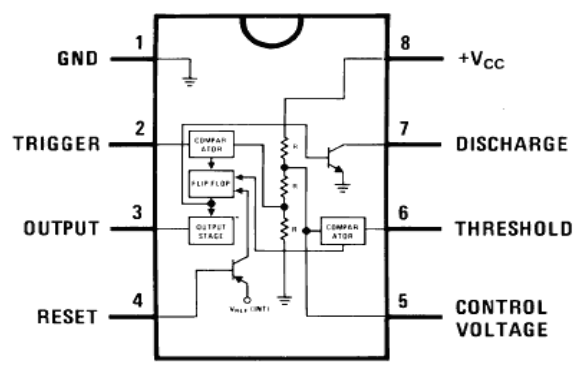

Gambar 3. Konfigurasi Pin IC NE 555

Spesifikasi dari pin IC NE 555 dapat dilihat pada data sheet IC NE 555.

Dalam aplikasinya, IC NE 555 salah satunya dapat beroperasi dalam mode astable multivibrator. Astable multivibrator adalah rangkaian yang menghasilkan bentuk gelombang yang menghasilkan bentuk gelombang periodic yang spesifik, misalnya gelombang kotak, segitiga, gigi gergaji atau sinusoidal. Astable multivibrator berfungsi sebagai pemicu/trigger transistor yang bekerja sesuai dengan besarnya duty cycle yang diinginkan.

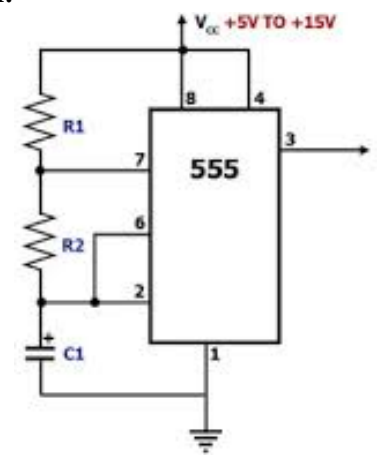

Gambar 4. Astable Multivibrator

Pada rangkaian gambar 4, rangkaian tersebut sering digunakan sebagai osilator gelombang kotak / pembangkit pulsa. Untuk menghitung nilai frekuensi pada rangkaian tersebut digunakan rumus :

$f=\frac{1}{t}$.

$t=0,7 *\left(R_{1}+2 * R_{2}\right) * C$

Jika persamaan (1) dan (2) disubsitusikan maka,

$f=\frac{1}{0,7 *\left(R_{1}+2 * R_{2}\right) * C}$

Dimana :

$\mathrm{F}=$ frekuensi $(\mathrm{Hz})$ 


$$
\begin{aligned}
& \mathrm{T}=\text { perioda gelombang (detik) } \\
& \mathrm{R}_{1} \text { dan } \mathrm{R}_{2}=\text { resistor rangkaian } \\
& \text { (Ohm) } \\
& \mathrm{C}=\text { kapasitor rangkaian }(\mathrm{Farad} / \mathrm{F})
\end{aligned}
$$

\section{Foto Dioda}

Fotodioda adalah jenis dioda yang berfungsi mendeteksi cahaya. Fotodioda merupakan sensor cahaya semikonduktor yang dapat mengubah besaran cahaya menjadi besaran listrik. Fotodioda merupakan sebuah dioda dengan sambungan pn yang dipengaruhi cahaya dalam kerjanya. Cahaya yang dapat dideteksi oleh fotodioda ini mulai dari cahaya infra merah, cahaya tampak, ultra ungu sampai dengan sinar-X (Susanto, 2010).

Prinsip kerja dari fotodioda jika sebuah sambungan-pn dibias maju dan diberikan cahaya padanya maka pertambahan arus sangat kecil sedangkan jika sambungan pn dibias mundur arus akan bertambah cukup besar. Cahaya yang dikenakan pada fotodioda akan mengakibatkan terjadinya pergeseran foton yang akan menghasilkan pasangan electronhole dikedua sisi dari sambungan. Ketika elektron-elektron yang dihasilkan itu masuk ke pita konduksi maka elektron-elektron itu akan mengalir ke arah positif sumber tegangan sedangkan hole yang dihasilkan mengalir ke arah negatif sumber tegangan sehingga arus akan mengalir di dalam rangkaian. Besarnya pasangan elektron ataupun hole yang dihasilkan tergantung dari besarnya intensitas cahaya yang dikenakan pada fotodioda (Hermawan, 2010).

Gambar 5 menunjukkan bentuk fotodioda yang digunakan dalam pembuatan rangkaian Receiver :

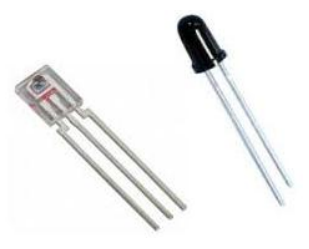

Gambar 5. Foto Dioda
Dalam pembuatan sensor infra merah ini, foto diode dihubungkan kepada rangkaian komparator / pembanding sehingga jika fotodioda tidak terkena cahaya, maka tidak ada arus yang mengalir ke rangkaian pembanding. Jika photodiode terkena cahaya maka photodiode akan bersifat sebagai tegangan, sehingga Vcc dan photodiode tersusun seri, akhirnya terdapat arus yang mengalir ke rangkaian pembanding. Dalam Technical Data Sheet IR Receiver TSOP 2523, Foto diode akan merespon cahaya infrared dengan gelombang $38 \mathrm{kHz}$.

Alat yang mirip dengan fotodioda adalah fototransistor (Phototransistor). Fototransistor ini pada dasarnya adalah jenis transistor bipolar yang menggunakan kontak (junction) base-collector untuk menerima cahaya. Komponen ini mempunyai sensitivitas yang lebih baik jika dibandingkan dengan Fotodioda. Hal ini disebabkan karena elektron yang ditimbulkan oleh foton cahaya pada junction ini diinjeksikan di bagian Base dan diperkuat di bagian Kolektornya. Namun demikian, waktu respons dari fototransistor secara umum akan lebih lambat dari pada fotodioda .

\section{METODOLOGI}

\section{Metode Penelitian}

Rangkaian yang dipakai dalam pembuatan alat system kontrol gerakan feeder pada mesin pencacah jerami berbasis magnetic clutch dan infra red detector ini adalah sebagai berikut :

\section{Rangkaian Sensor Infrared}

Pada rangkaian pemancar infrared (transmitter) digunakan IC NE555 dengan memanfaatkan aplikasi IC NE555 sebagai astable multivibrator. Berdasarkan Technical Data Sheet IR Receiver TSOP 2436 rangkaian pendeteksi cahaya infrared (IR detector / receiver) hanya merespon cahaya infra merah dengan frekuensi 38 $\mathrm{kHz}$ keatas, maka sinyal infrared yang dibuat juga harus dengan frekuensi $38 \mathrm{kHz}$. 
Berdasarkan rumus persamaan (2), dengan memberikan nilai $\mathrm{R}_{2}=1 \mathrm{kOhm}$ dan nilai $\mathrm{C}$ $=10 \mathrm{nF}$ dapat diketahui nilai $\mathrm{R} 1$ yang harus diberikan, yaitu

$$
\begin{aligned}
& 38000=\frac{1}{0,7 *\left(R_{1}+2 * 1 * 10^{3}\right) * 10 * 10^{-9}} \\
& R_{1}=1759,3948 \mathrm{Ohm}
\end{aligned}
$$

Karena nilai R1 yang diperoleh adalah 1759,3948 Ohm, sedangkan nilai ini tidak ada di pasaran, maka pada desain ini digunakan tahanan variable (trimpot) 2 kOhm. Kita sebenarnya dapat memilih menentukan besar $\mathrm{C}$ atau $\mathrm{R} 2$ terlebih dahulu, tetapi disarankan untuk menentukan $\mathrm{C}$ saja karena jika yang dihitung adalah $\mathrm{C}$ biasanya nilainya sulit ditemukan dipasaran, sedangkan nilai $\mathrm{R}$ dapat menggunakan $\mathrm{R}$ variable.

Dari hasil perhitungan diatas, dapat dibuat rangkaian seperti terlihat pada gambar 6 berikut :

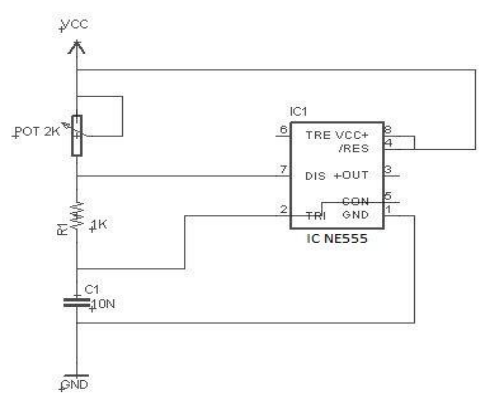

Gambar 6. Rangkaian Pemancar Infrared Dari rangkaian astable multivibrator tersebut dapat dibuat rangkaian transmitter dan receiver seperti gambar 7 dan gambar 8 berikut :

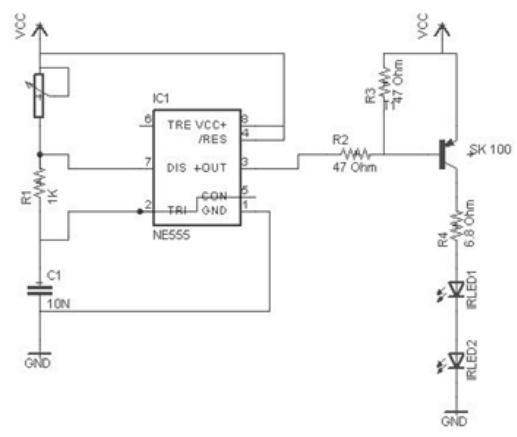

Gambar 7. Rangkaian Transmitter

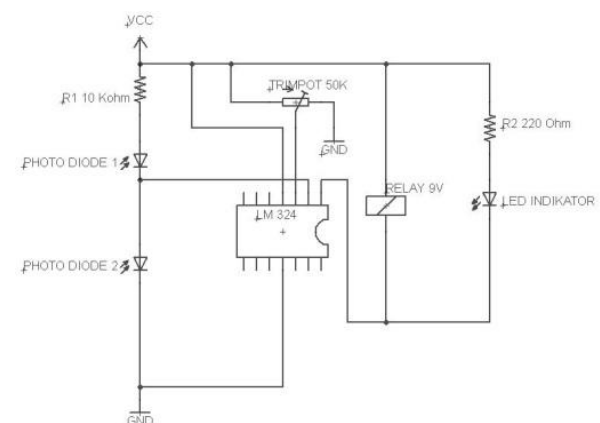

Gambar 8. Rangkaian Receiver

Pada rangkaian receiver, digunakan Foto Diode sebagai penerima sinar infra red. Pada rangkaian ini terdapat rangkaian komparator (pembanding) yang mana dalam rangkaian tersebut digunakan IC LM324 yang berfungsi sebagai pembanding tegangan keluaran dari foto diode. Karena rangkaian pembanding membutuhkan tegangan referensi, maka digunakanlah trimpot. Pada rangkaian ini digunakan LED sebagai indicator output.

Prinsip kerja rangkaian ini yaitu Ketika rangkaian transmitter dan receiver di beri tegangan 5 volt, maka rangkaian akan aktif. Pada rangkaian transmitter, infra red akan memancarkan sinar infra merah yang akan ditangkap oleh photo diode. Ketika photo diode menangkap cahaya, maka photo diode akan bersifat konuktansi, sehingga Vcc dan photodiode tersusun seri, sehingga terdapat arus yang mengalir ke rangkaian pembanding (komparator). Karena tegangan yang dihasilkan sensor lebih dari tegangan referensi yang telah di set oleh trimpot terhadap komparator (LM324), maka rangkaian output komparator akan mengeluarkan tegangan nol, sehingga indicator LED akan OFF. Ketika suatu objek melewati rangkaian maka cahaya infra red akan terhalang. Jika cahaya infra merah terhalang, maka photo diode tidak konduktansi.

\section{Magnetic Clutch}

Magnetic clutch ini bertujuan untuk mengatur gerakan feeder yang akan mengumpankan jerami ke mesin pemotong. Sifat yang dimanfaatkan adalah induksi magnet yang menginduksi stator coil magnetic clutch jika diberi tegangan. 
Magnetic Clutch yang digunakan pada feeder mesin pencacah jerami ini adalah Magnetic Clutch Type BH-2.6 yang diproduksi oleh Shinko Electric Co. Menurut data sheet Clutch BH-2.6, tegangan yang dibutuhkan adalah 24 VDC dengan daya konsumsi sebesar $4,8 \mathrm{~W}$, besarnya induksi magnet dari magnetic clutch ini adalah 4,16 . 10-3 Tesla.

Pada perencanaan alat kontrol gerakan feeder pengumpan jerami menggunakan sensor infra red ini dapat dilihat pada gambar 9.

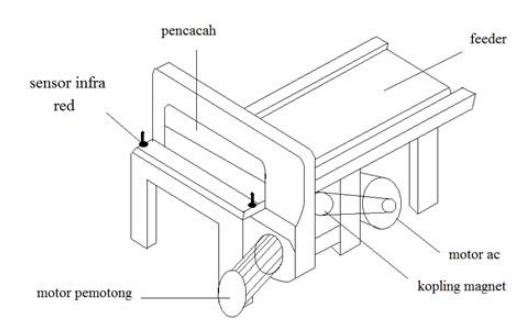

Gambar 9. Rancangan Alat Kontrol Gerakan Feeder Pengumpan Jerami Menggunakan Sensor Infra Red

Prinsip kerja alat ini adalah motor DC menggerakkan pulley pada kopling magnet. Jika sensor infra red tidak mendeteksi sinyal jerami, maka arus listrik akan mengalir ke stator coil pada kopling magnet dan mengubah stator coil menjadi magnet listrik yang akan menarik pressure plate dan bidang singgungnya akan bergesekan dan saling melekat dalam satu unit terhadap pulley. Pada posisi ini feeder akan bergerak mengumpan jerami ke pencacah. Ketika jerami yang diumpankan melewati sensor, maka sensor akan memberi perintah pemutusan arus listrik pada stator coil kopling magnet, sehingga sifat magnet listrik stator coil menghilang dan melepaskan tarikan terhadap pressure plate. Pada posisi ini stator tidak lagi ikut berputar karena bidang singgungnya tidak lagi melekat dengan pulley yang menyebabkan feeder berhenti. Setelah jerami dipotong oleh mesin pencacah, maka sensor infra red kembali tidak mendeteksi sinyal jerami, sehingga feeder kembali bergerak mengumpan jerami.

\section{HASIL DAN PEMBAHASAN}

Pengujian rangkaian infrared dilakukan dengan menggunakan kamera seperti terlihat pada gambar 10 .
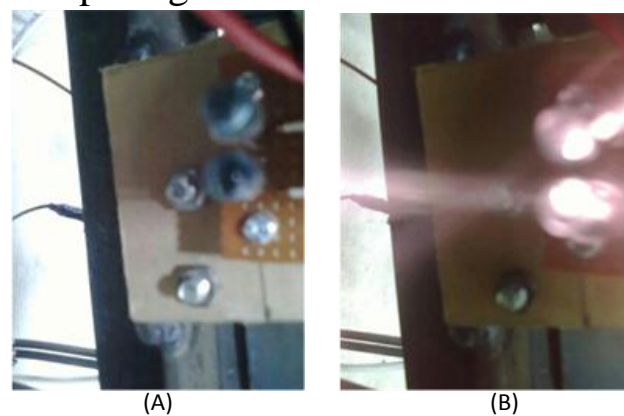

Gambar 10. Pengujian sensor infra red dengan kamera (a) Sensor Infrared dalam posisi OFF

(b) Sensor Infrared dalam posisi ON

Dari gambar 10, dapat dilihat bahwa sensor infrared akan memancarkan sinar infrared jika diberi tegangan $5 \mathrm{~V}$ DC yang tertangkap oleh kamera. Sinar infrared inilah yang akan dipancarkan pada receiver (foto diode) dan mengolah sinyal keluaran melalui rangkaian komparator. Ketika foto diode menerima cahaya infrared dari transmitter, maka keluaran rangkaian komparator akan berlogika 1, sedangkan ketika foto diode tidak menerima cahaya infrared dari transmitter, maka keluaran rangkaian komparator akan berlogika 0 .

\section{Pengujian Magnetic Clutch}

Sitem kerja magnetic clutch yaitu puli pada clutch akan terus berputar jika dihubungkan pada motor penggerak. Dalam keadaan tidak diberi tegangan listrik, stator coil magnetic clutch tidak bersifat magnet sehingga tidak menarik plessure plate. Dalam keadaan ini feeder tidak akan bergerak. Keadaan ini dapat terlihat pada gambar berikut ini :

Saat magnetic clutch diberi tegangan $25 \mathrm{~V}$ DC, maka stator coil akan menarik plassure plate, sehingga bidang singgungnya saling bergesekan dan saling melekat dalam satu unit. 
Hasil pengujian magnetic clutch dapat dilihat pada tabel 1 .

Tabel 1. Hasil Pengujian Magnetik Clutch

\begin{tabular}{|l|lr|l|}
\hline No. & $\begin{array}{l}\text { Keadaan } \\
\text { Diuji }\end{array}$ & Yang & $\begin{array}{l}\text { Hasil } \\
\text { Pengujian }\end{array}$ \\
\hline 1. & $\begin{array}{l}\text { Magnetic Clutch } \\
\text { tanpa supply 25 V }\end{array}$ & $\begin{array}{l}\text { Stator } \\
\text { Coil tidak } \\
\text { Menarik } \\
\text { Plesure } \\
\text { Plate }\end{array}$ \\
\hline 2. & $\begin{array}{l}\text { Magnetic Clutch } \\
\text { tanpa supply 25 V }\end{array}$ & $\begin{array}{l}\text { Stator } \\
\text { Coil tidak } \\
\text { Menarik } \\
\text { Plesure } \\
\text { Plate }\end{array}$ \\
\hline
\end{tabular}

Dari hasil pengujian diatas dapat disimpulkan bahwa magnetic clutch bekerja dengan baik. Ketika stator coil menarik pleasure plate, maka stator coil akan ikut bergerak bersama dengan puli yang digerakkan oleh motor dc, sehingga feeder yang dihubungkan dengan gear terhadap stator coil akan ikut bergerak.

\section{Pengujian Pemotongan Jerami Tanpa Feeder}

Pengujian pemotongan jerami tanpa feeder dilakukan dengan mengumpankan jerami dengan tangan pada pemotong. Hasil percobaan ini menghasilkan potongan jerami yang tidak seragam dan melebihi ukuran yang diinginkan $(2-5 \mathrm{~cm})$. Hasil pemotongan jerami tanpa feeder dapat dilihat pada gambar 11 .



Gambar 11. Hasil pemotongan tanpa fedeer

\section{Pengujian Pemotongan Jerami Menggunakan Feeder}

Pengujian pemotongan jerami menggunakan feeder ini dilakukan dengan cara mengumpankan jerami menggunakan feeder pada mesin pemotong. Hasil pemotongan ini menghasilkan potongan jerami sesuai dengan target $2-5 \mathrm{~cm}$. hasil pemotongan jerami menggunakan feeder dapat dilihat pada gambar 12 .

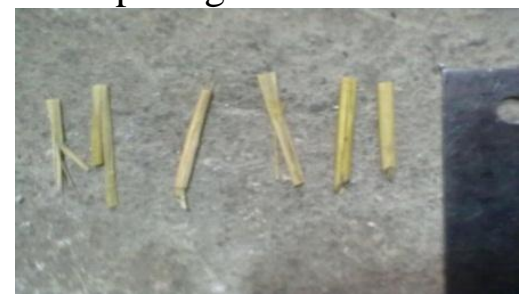

Gambar 12. Hasil pemotongan jerami dengan fedeer.

\section{SIMPULAN}

Setelah melakukan pembuatan alat percobaan, maka diperoleh kesimpulan, bahwa fedeer ini dapat bekerja sesuai dengan perencanaan.

\section{UCAPAN TERIMA KASIH.}

Ucapan terima kasih penulis sampai kepada Direktorat Penelitian dan Pengabdian kepada Masyarakat, Dirjen Dikti Kementerian Pendidikan Nasional yang telah membiayai penelitian ini, dengan nomor kontrak: No. 116/PL9.1.4/LT/2015

\section{DAFTAR PUSTAKA}
Bahan Pelatihan Nasional Otomotif, Perbaikan Kendaraan Ringan, "Electrical, Pengaman sirkuit kelistrikan", Jakarta,2003.

Direktorat Jendral Pembinaan Pelatihan dan Produktifitas, "Memelihara/Servis Sistem AC (Air Conditioner) Mobil", Jakarta, 2009.

Djoekardi, Djuhana:'Mesin-Mesin Listrik", Penerbit Universitas Trisakti, Jakarta, 1996. 
Hermawan, Ali, 'Infra Merah Pada Remote

Control', Gramedia, Bandung, 2010.

Hermawan Ali, 'Sistem Sensor Infra

Merah“", Gramedia, Bandung, 2009.

Komar, Abdel, “Teknologi Pengolahan Jerami” Yayasan Dian Grahita Indonesia, Bandung, 1984.

Mochtar, Wijaya "Dasar-Dasar Mesin Listrik”, Djambatan, Jakarta, 2001.

Rahmawan, Rizqi "Sistem Kontrol Produk Gas Metana pada Digester Tipe Fixed Dome" Fakultas Teknik, Universitas Brahmawijaya, 2011.

Riyadi Slamet, ST, MT . "Diklat Kuliah Motor Listrik", Perpustakaan Unika, Soegijapranata, 2007.

Shen, L. C.,. "Aplikasi Elektromagnetik", Jilid 1 Edisi Ketiga, Erlangga, Jakarta, 1996..

Simatupang Ray, "Rangkaian Elektronika Remote Control IR", http://www.elektronikamodern.com/r angkaianinframerah.html, Riau, 11 Mei 2014.

Susanto ,Wibiseno Koselan, "Infra Merah Receiver" Seminar Nasional, ITS, 2010. 